2014-6

\title{
Undertaking Action Research in Prison: Developing the Older prisoner Health and Social Care Assessment and Plan
}

\author{
Kate O'Hara \\ Technological University Dublin, kate.ohara@mydit.ie \\ Elizabeth Walsh \\ University of Leeds \\ Katrina Forsyth \\ University of Manchester
}

See next page for additional authors

Follow this and additional works at: https://arrow.tudublin.ie/aaschsslarts

Part of the Political Science Commons, and the Sociology Commons

\section{Recommended Citation}

O'Hara et al. (2014) Undertaking action research in prison: Developing the Older prisoner Health and Social Care Assessment and Plan, Action Research vol. 12 no. 2 pp.136-150. doi:10.1177/

1476750314524006

This Article is brought to you for free and open access by the Social Sciences at ARROW@TU Dublin. It has been accepted for inclusion in Articles by an authorized administrator of ARROW@TU Dublin. For more information, please contact arrow.admin@tudublin.ie, aisling.coyne@tudublin.ie,gerard.connolly@tudublin.ie.

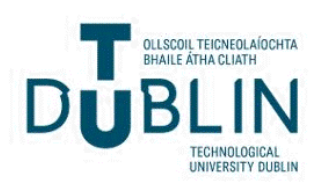




\section{Authors}

Kate O'Hara, Elizabeth Walsh, Katrina Forsyth, Jane Senior, and Jenny Shaw

This article is available at ARROW@TU Dublin: https://arrow.tudublin.ie/aaschsslarts/61 


\title{
Undertaking action research in prison: Developing the Older prisoner Health and Social Care Assessment and Plan
}

Elizabeth Walsh, Katrina Forsyth, Jane Senior, Kate O'Hara and Jenny Shaw

\begin{abstract}
Older prisoners are the fastest growing group in prisons. They have complex health and social care needs and the coordination of their care is suboptimal. An action learning group including health care staff, prison staff and older prisoners was established at one prison in England. The group developed the Older prisoner Health and Social Care Assessment and Plan (OHSCAP) which is a health and social care assessment and care planning process for the better identification and management of older prisoners' needs. This paper describes and critically analyses the process of action learning in prison to develop and pilot the OHSCAP. Data were collected through reflective notes from the action learning group facilitator, reflective diary writing from group members, emails, research project steering group meeting notes and interviews with action learning group members. The constant comparison method of data analysis was used.
\end{abstract}

We found that action learning is a valuable approach for developing practice in the challenging prison environment. There are important considerations when using action learning in the prison setting. These include maintaining the groups' focus; clarifying roles and procedures; providing practical and theoretical space and considering the groups' composition.

Keywords: Action, learning, prison, prisoners, older, health, social, assessment, care planning 


\section{Introduction}

There has been a marked rise in the number of older prisoners in the majority of developed countries across the world (American Civil Liberties Union, 2012; Grant, 1999; Ministry of Justice, 2004, 2013; Uzoaba, 1998). For example, in England and Wales the percentage of sentenced prisoners aged 60 and over rose by over 100 per cent between 2002 to 2011 (Ministry of Justice, 2012). Consequently, adults aged 60 and over are the fastest growing age group in the English and Welsh prison estate (Ministry of Justice, 2013). This is as a result of an aging population; the use of indeterminate sentencing; the court sentencing an increasing number of older adults to prison for longer periods of time and improvements in forensic science techniques resulting in older adults being convicted for crimes they committed as younger individuals (Ginn, 2012). The rise in numbers of incarcerated older adults poses challenges for prison and health care staff who are required to appropriately meet the complex health and social care needs of older adults within the challenging prison environment.

In a recent project to develop an assessment tool and care planning process to support the health and social care of older prisoners, an action learning group was used to support its development and piloting. In this paper we focus our attention on the process and outcomes of action learning as a method to support the development of the tool and care planning process in the prison setting rather than reporting on the actual content development of the tool. Detailed information regarding the content development of the OHSCAP tool can be found elsewhere (see Senior et al., 2013). 


\section{Background}

Older adults in prison have multi-faceted health needs (Fazel et al. 2001; 2004). They have higher rates of morbidity than both younger prisoners and those of a similar age living in the community (Fazel et al., 2001). Over 80 per cent of older prisoners have at least one major illness (Fazel et al., 2001). These most commonly include cardiovascular diseases, arthritis, respiratory diseases and endocrine disorders (Loeb \& AbuDagga, 2006). In addition, it is estimated that over half of older prisoners have a psychiatric diagnosis with depressive illness being the most commonly diagnosed (Fazel, Hope, O Donnell, \& Jacoby, 2001).

There is a paucity of research regarding older prisoners' social care needs. Older prisoners frequently suffer from mobility difficulties which are exacerbated by the narrow doorways; long walks and lack of hand rails in prison (Snyder, Van Wormer, Chadha, \& Jaggers, 2009). They may also experience incontinence and a lack of appropriate services to support them with this issue (Williams, 2012). Hayes (2010) reported that, in his sample of 262 older prisoners, more than a third had some level of functional need in activities of daily living, and 14 per cent had mobility difficulties. Nearly half were imprisoned in a geographical area far from their home, which made contact with their social support networks extremely difficult. Social care provision for older prisoners is lacking and is often inappropriately seen as the responsibility of health care departments, as opposed to a wider multi-agency obligation (Her Majesty's Chief Inspector of Prisons [HMCIP], 2008).

There have been repeated calls for a national strategy for older prisoners (HMCIP, 2008); however, to date this has not been realised. The Department of Health (2007) have 
produced a toolkit for good practice for older prisoner care. The guidance recommended the use of specific health and social care assessments especially designed for older prisoners' needs and that these should be repeated at least every six months, with care plans developed and reviewed. In spite of this guidance only 19 per cent of prisons holding adult males have implemented such an assessment (Senior et al., 2013). Consequently, health and social care provision in prison predominately relies on information obtained via a generic, screening instrument used at reception (Grubin, Carson, \& Parsons, 2002). There are specific adaptations of the instrument for men and women; however there are no specific versions for older prisoners. Furthermore, social care needs are excluded from the generic assessments. Prior research has shown that, if health problems are not identified at reception into prison, they are unlikely to be detected later during a person's time in custody (Birmingham, Mason, \& Grubin, 1997). There is therefore a need for specialised assessments and care planning for the effective identification and management of older prisoners' health and social care needs following reception into custody.

\section{Action Research and Action Learning}

The OHSCAP was developed utilising action learning and action research techniques. According to Meyer (2010) action research is an approach to research rather than a specific method of data collection, underpinned by cycles of planning, acting, observing, reflecting and re-planning. Authors have referred to these cycles as a spiral because action research is a continuous and iterative process (Altricher, Kemmis, McTaggart, \& Zuber-Skerritt, 2002) 'that alternates continuously between enquiry and action as part of the research process', (Munn-Giddings C, McVicar, \& Smith, 2008, p.466). Meyer suggests that 'action research typically blurs the boundaries between education, practice and research' (Meyer, 2010, 
p.258) where practitioners and researchers work closely together to innovate, develop and manage changes in practice. According to Bucknall, Kent, and Manley (2008) emancipatory action research integrates reflection and critique, action spirals, strategic intent and collaboration with stakeholders where the research approach is characterised by participation, collaboration and inclusion.

Action learning has been used in a wide range of areas, such as in supporting the development of clinical leadership (Edmonstone, 2008); developing mental health services (Lamont, Brunero, \& Russell, 2010) and in supporting student nurses (Heidari \& Galvin, 2003). It has also been successfully used in the prison setting with both health care and discipline staff in developing practice and promoting collaborative working (Giblin, Kelly, Kelly, Kennedy, \& Mohan, 2012; Walsh \& Bee, 2012; Walsh \& Freshwater, 2006, 2009; Walsh, 2009). Given its value in supporting reflection, learning and development, action learning can be used as a method of simultaneously developing practice and collecting data in action research projects. The authors are not aware of any previous research that has involved prison staff, NHS staff and prisoners working collaboratively in an Action Learning Group.

\section{Approach to research}

An action learning group comprising prison health care staff (nurses and health care assistants), prison officers and older prisoners was established at one adult male prison in England. Project facilitators held an open meeting in the prison to introduce health care and discipline staff to the project and to ascertain interest in joining the action learning group. Information about the wider project was given to those who attended, in addition to information about the value and process of action learning. At the first action learning 
group, 14 people attended including two older prisoners, primary health care staff, a Governor, prison officers from residential areas, the gym and first night centre. There was consistent representation throughout the life of the group from prison officers and older prisoners; however, the involvement of health care staff reduced significantly as the project progressed. Upon reflection, the facilitator attributed this to the focus on social care rather than health care.

The action learning group met monthly between November 2010 and April 2011 with an experienced facilitator (EW) to develop the assessment tool which was then piloted in practice for 12 months with three interim meetings to refine and amend the tool in light of feedback from the pilot. The tool was piloted again until the group met in October 2011 when minor amendments were agreed. Another piloting phase was undertaken with the tool and the group met again in January 2012 to receive more feedback. The group met for a final time in March 2012 when the assessment tool was 'signed off' by all members present and the group disbanded.

Due to the inclusion of serving prisoners in the action learning group, the venue for meetings had to be inside the prison. The first two meetings were held in the prison chapel however, it became clear that this was unsuitable for the work given its large size and lack of table top workspace, and the group moved into a smaller, more appropriate room.

Given its iterative nature and need for transparency, action research requires the collection of data from various sources throughout the development phases in order for each cycle to inform the next. Therefore, in this part of the study, data were collected through reflective notes from the action learning group facilitator, reflective diary writing from group members, emails, research project steering group meeting notes, and interviews with action 
learning group members. These sources all contributed to the analysis of the actual process of action learning and the development of the assessment tool.

Following action learning group activity and piloting of the OHSCAP, semi structured interviews were undertaken with action learning group members and to ascertain experience of action learning and to evaluate the OHSCAP. Six Action Learning Group members were interviewed including Prison Officers, health care staff and prisoners. Two of these interviews were held face-to-face and the remainder were conducted over the telephone. Interviews were audio recorded and lasted between 20 minutes and one hour. All qualitative data were analysed using the constant comparison method of analysis (Holloway \& Todres, 2010) and the computer software NVivo was used to conduct the analysis. Data were analysed until theoretical saturation was reached. Analysis of the data uncovered themes in two distinct areas: the use and experience of action learning to develop the tool and the actual developing/piloting of the assessment tool. This paper focuses upon the former area.

\section{Findings and discussion}

Four sub themes emerged from the data analysis pertaining to the experience of action learning to develop an assessment tool in the prison setting: maintaining focus, seeking clarity, space and group composition.

\section{Maintaining focus}

Facilitating the group to maintain the focus of their work was at times challenging. The group had a tendency to solve specific issues as they arose rather than focus on a system to manage them. For example, in discussing the key components of the assessment tool, 
mobility was identified as an important area to address. The potential issues around mobility included lack of seating on the exercise yard. The group immediately began to consider solutions. Whilst generating practical solutions is considered to be one of the functions of an action learning group, the move away from considering mobility in more general terms for the purpose of developing an assessment tool to focussing on one particular prisoners' issue, was commonplace in the group, and was managed through facilitation in bringing the group back to the wider discussion. Interesting, even within the interviews with action learning group members, interviewees (particularly prisoners and prison officers) found the notion of reflecting on the OHCSAP challenging and tended to focus on the specfic issues faced by older prisoners. Again, it was necessary for the interviewer to continually steer the focus of the interview back to the OHSCAP and action learning experience.

Facilitating action learning within prison can be challenging. The closed nature of prison, both physically through locked gates and bars, and psychologically due to the need for staff and prisoners to remain emotionally detached, leads to reluctance to engage with open methods that have reflection and transformation at their core (Freshwater, Cahill, Walsh, Muncey, \& Esterhuizen, 2012). The nature of a closed system is such, that practice is outcome driven and task orientated which we suggest links directly with behaviours that Menzies-Lyth refers to as defences against anxiety (Menzies-Lyth, 1988). These include denial of feelings and a desire to engage in ritual task performance to eliminate the need for decision making. Denial of feelings protects prison staff from acknowledging the challenging and stressful nature of their work. Engaging in ritual task to eliminate the need to make decisions is supported in prison by an overarching prison regime that dictates the running of 
the establishment. Therefore, by focussing on tasks and outcomes staff are able to remove themselves from reflecting on their own practice and focus on getting specific actions completed, to achieve a tangible outcome.

The culture within which prisoners live and work provided a further challenge relating to maintaining focus. Whilst there is a move within prison health care settings to involve prisoner patients in health care through patient participation and involvement strategies (Cowman \& Walsh, 2013), requesting staff and prisoner involvement in policy and practice development is still in its infancy. Therefore, in a culture that is traditionally and predominantly autocratic rather than democratic, we found that staff and prisoners will paradoxically lose focus when asked to contribute to development and turn their attention to more tangible activity.

With group members finding difficulty in maintaining focus, the facilitator worked with them to identify and appreciate other benefits to action learning in terms of interprofessional working and understanding of each other's roles and perspectives. This was particularly noted by one of the action learning group members who stated that:

'I think it (the action learning group) did raise the profile of the older prisoner, certainly on A Wing (the vulnerable prisoner wing), in the fact that possibly their health needs were somewhat different to their more younger counterparts' (Action Learning Group Staff member).

The value of action learning in raising awareness of other perspectives, was clearly noted by group members and concurs with Hoogwerf, Frost, \& McCane (2010, p.52) who state that 
'by engaging in action learning, health professionals can learn, among other things, each other's language and develop an insight into each other's professional knowledge'.

\section{Seeking clarity}

During discussion of the development of the assessment tool, action learning group members were asked to consider who they felt would be the most appropriate person to undertake the assessment. This encouraged them to begin to think about roles and responsibilities when caring for older prisoners. Reflection on the roles and working practices of the wider prison officer population, led to a more in-depth, almost philosophical discussion about the role of the prison officer, where reflection on their own roles were minimal:

This led to conversation about the barriers to caring for older prisoners e.g. cultural issues and the risks of [prison officers] being seen to be caring e.g. pushing wheelchairs, collecting meals etc. (Facilitator notes, December 2010).

The group did not reflect on their own particular roles to any great depth, which could possibly be construed as a defence against anxiety (Menzies-Lyth, 1988) but instead concentrated on the difficulties of prison officers presenting a caring approach to their work with older prisoners. By doing this, group members reflected more generically about prison officers and therefore removed the personal aspect of reflection. The facilitator felt that the group readily engaged with this approach as a way to avoid sharing personal reflections on practice, another defence against anxiety.

Action learning group members also required clarity in understanding the collection and sharing of information regarding older prisoners. Challenges to the flow of information 
around the prison were discussed at length and identification of these particular issues informed the development of the screening tool in terms of its operationalisation. Following reflection on roles, responsibility and information collection within the prison, group members were quite surprised to learn that information pertaining to the assessment of older prisoners was routinely collected by reception staff and first night centre staff. The group concluded that it was the effective communication between staff was lacking:

'In some ways much of the information we would expect to be collected regarding the older prisoner, is already collected. The group cannot see any huge gaps in the information. However, what they have decided is missing, is effective communication of the information' (Facilitator notes, January 2011).

However, of more interest to us in this paper is the way in which the need to gain clarity around roles, responsibilities and the movement of information led to facilitated reflection on practice for group members. Encouraging prison staff to reflect on their own practice can be challenging, however, when framed through an action learning process with a specific aim (developing an assessment tool and care planning process), broad superficial reflection took place readily. Reflection on own practice was less easy for group members.

Space

Given the reflective nature of action learning, it is important that action learning group meetings are held somewhere that members feel comfortable to reflect on practice, discuss issues and express emotion (McGill \& Brockbank, 2004). Snoeren, Niessen, \& Abma (2011) note the importance of a communicative space in action research, which promotes free and uninhibited communication. This is particularly important where there is potential for 
conflicting power issues between participants. As the focus for this action learning group was the development of the assessment tool and care planning process, it was important that the space for meetings also enabled and facilitated creative thinking. Initial meetings were held in an open plan area with no tables, just seating. This was felt to stifle creativity and reduced the possibility of smaller group work activity as it promoted a more formal atmosphere. Indeed, after the first meeting the facilitator noted:

'We need to move the venue to somewhere that we can have tables and flip charts to get creative' (Facilitator notes, November 2010).

Once the meeting was moved to a smaller room which had tables, it was noted by one of the action learning group members that this was an improvement:

'The location of the meeting was better as we had tables to work on. I still think there is a lot of ground to cover but I really enjoyed the last meeting. I am glad to be part of the development of this assessment' (Action learning group member reflective diary entry).

Although the physical space was different, it was felt by the facilitator that the psychological space provided by the action learning group time was important to members, particularly because the autocratic prison environment provides limited opportunity for such reflection. The action learning space enabled group members to take a step back from the daily workload and encouraged them to reflect on individual and organisational practices. In needing to consider how the assessment tool and care planning process would work in practice, group members were required to consider what assessments were currently in place for older prisoners and how practices were enacted. This space enabled group 
members to uncover 'taken for granted' practices and consider their practice in more depth, thus providing insight:

'After some general discussion about the venue and dates of subsequent meetings, the group began to consider current practices that occur in the prison as regards older prisoners. Although they initially stated that there were no specific processes in place for managing/assessing older prisoners on reception, it became clear that there were' (Facilitator notes, November 2010).

Group composition

The group dynamics in an action learning group are important to understand if facilitation is to be successful (McGill \& Brockbank, 2004). The action learning group comprised prison officers, prisoners and health care staff. Given the inclusion of both prisoners and prison officers, there was potential for power and authority to influence the discussion and hence the development of the assessment tool and care planning process. In order to reduce the impact that this power imbalance might have on the group and its work, a set of ground rules were agreed at the start of the group, thus promoting a space where group members felt safe to talk and reflect.

Health care staff and senior management attendance at the monthly action learning group meetings was not consistent. Indeed, towards the latter end of the life of the group, no health care staff attended. There were some concerns that the lack of senior staff involvement may have an impact on the implementation of the intervention.

'My concern was that it maybe wouldn't carry as much kudos because there wasn't sort of high seniority there' (Action learning group member). 
Although disappointing, other group members felt that it was not an issue, and indeed a smaller group was deemed beneficial:

'The meeting was small last month. I felt this helped and we were able to move forward more quickly with things' (Action learning group member diary entry).

From the facilitator perspective, the inconsistent attendance was deemed not to have had an impact on the rest of the group:

'Again, attendance was not ideal; however, those who are attending regularly remain enthusiastic' (Facilitator notes, January 2011).

This perspective was supported by the findings from the interviews with the action learning group members who felt it was more important that the staff who attended were interested in developing support for older prisoners rather than ensuring equal representation from health care and prison staff.

'And staff wise, I think it's more important that staff are interested in what you're doing rather than having specific qualifications...If somebody's interested then you're more likely to get better work out of them, rather than 'Well I'm in this role but I'm not really interested in it' (Action learning group member).

For the majority of the life of the group, it consisted of prison officers and prisoners. Although for some of the tool development and piloting, the health care perspective was missing, it was felt that having the prisoner perspective in the group was important and valuable. One of the prisoner group members noted how the group was a positive experience where they were encouraged to contribute: 
'Yeah, they [prisoner action learning group members] didn't feel as if they were intimidated in any way from the officers or from the members that were there at all, they were encouraged to voice their opinions' (Action learning group prisoner member).

Whilst the lack of health care involvement in the majority of the development of this tool could have been perceived as problematic, it was felt to have minimal impact. Health care information from all prisoners is collected and their health care needs assessed quite quickly on entry into prison. What became clear through this work was the lack of social care assessment and provision for older prisoners. The lack of health care input into the development of the tool enabled prison officers and prisoners to focus particularly on those aspects of need that were not being met or assessed appropriately, namely social care needs. The composition of the group meant that whilst the tool was being developed, discussion regarding broader issues for older prisoner, such as the lack of seating on the exercise yard, took place. As there were staff in the group who could effect change quickly, solutions were found to these problems. The social care needs of older prisoners have been in appropriately seen as the responsibility of health care staff as opposed to a wider disciplinary responsibility (Her Majesty's Chief Inspector of Prisons, 2008). The reduced health care involvement provided an opportunity for Prison Officers to take responsibility for some of older prisoners' social care needs and created a system for Prison Officers to effectively work in conjunction with health care staff to care for older prisoners. Such developments are necessary because there is a high level of ambiguity surrounding the responsibility for older prisoners' social care needs (Senior et al., 2013; Williams, 2012). 


\section{Conclusions}

In this paper, the use of action learning as an approach to developing a new assessment tool and care planning process for the health and social care of older prisoners has been explored. From feedback and reflection on the experience of action learning, four key themes have emerged which are: maintaining focus, seeking clarity, space and group composition. All are important to consider in taking forward knowledge generated regarding the use of action learning in the prison setting. Supporting a group to maintain a clear focus in action learning is a skill required of any action learning group facilitator, however, whilst it may appear that for an action learning group to lose focus, attention is taken away from the aim of the group, it can in fact be beneficial on many levels, especially in organisations where decision making and action can be slow and restricted through hierarchical government. Findings around seeking clarity and action learning group space have demonstrated the importance of psychologically safe spaces in prison for reflecting on practice. In order to ensure the effectiveness of the action learning group in prison, consideration needs to be given to its composition. Paying attention to potential challenges with power dynamics and interprofessional relationships is important. However, prisoners can be effectively and meaningfully involved in the development of health and social care initiatives in prison through action learning.

Action learning was successfully used to develop and implement the OHSCAP in a prison environment where changes to service delivery can be difficult due to the hierarchical structure and security driven focus. After a short time to settle into the work, this prison action learning group worked well in developing and piloting the assessment tool. The value of action learning as an approach to develop practice and relationships cannot be 
underestimated, however, there are issues which must be explored and addressed prior to its use in the challenging prison setting, if it is to work effectively.

\section{Acknowledgements}

The authors wish to thank the staff and prisoners who participated in this research project.

\section{Funding acknowledgement}

This project was funded by the National Institute for Health Research, Health Services and Delivery Research Programme (project number 08/1809/230).

Department of Health disclaimer

The views and opinions expressed therein are those of the authors and do not necessarily reflect those of the HS\&DR Programme, NIHR, NHS or the Department of Health.

Author biographies

Elizabeth Walsh is an Associate Professor in the School of Health Care at the University of Leeds. She is a qualified nurse with clinical, academic and practice development experience in prison health care settings. She is the Chair of the Royal College of Nursing, Nursing in Criminal Justice Services Forum and an Adjunct Professor at the School of Nursing, University of Ottawa, Canada. 
Katrina Forsyth is a Research Associate and PhD student at the Offender Health Research Network at the University of Manchester. Her research focuses on older prisoners. She holds a Masters degree in Research Methods.

Jane Senior is manager of the Offender Health Research Network, based at the University of Manchester. She is a qualified mental health nurse with clinical and academic experience in prisons, secure, acute and community mental health settings.

Kate O'Hara is an employment based postgraduate scholar at the Irish Penal Reform Trust completing her doctoral research in conjunction with Dublin Institute of Technology. She was previously a Research Assistant at the Offender Health Research Network at the University of Manchester.

Jenny Shaw is a Professor of Forensic Psychiatry and Academic Lead for the Offender Health Research Network at the University of Manchester. She is also Clinical Director for the Specialised Services Network and a Consultant Forensic Psychiatrist at Lancashire Care NHS Foundation Trust. 


\section{References}

Altricher, H., Kemmis, S., McTaggart, R., \& Zuber-Skerritt, O. (2002). The Concept of Action Research. The Learning Organisation, 9(3), 125-131.

American Civil Liberties Union. (2012). At America's Expense: The Mass Incarceration of the Elderly / American Civil Liberties Union. New York. Retrieved from http://www.aclu.org/criminal-law-reform/report-americas-expense-massincarceration-elderly

Birmingham, L., Mason, D., \& Grubin, D. (1997). Health screening at first reception into prison. Journal of Forensic Psychiatry, 8(2), 435-439.

Bucknall, T., Kent, B., \& Manley, K. (2008). Evidence and use and evidence generation in practice development. In K. Manley, B. McCormack, \& V. Wilson (Eds.), International Practice Development in Nursing and Healthcare (pp. 84-104). Oxford: Blackwell.

Cowman, A., \& Walsh, E. (2013). Patient and public involvement - Building a Successful User Involvement System in Prison Healthcare. Primary Health Care, 23(26-31).

Department of Health. (2007). A pathway to care for older offenders. A toolkit for good practice. London: Department of Health.

Edmonstone, J. (2008). Action learning as a developmental practice for clinical leadership. The International Journal of Clinical Leadership, 16, 59-64.

Fazel, S., Hope, T., O Donnell, I., \& Jacoby, R. (2001). Hidden psychiatric morbidity in elderly prisoners. British Journal of Psychiatry, 179, 535-539. Retrieved from <Go to $|S|>: / / 000172660500013$

Fazel, S., Hope, T., O’Donnell, I., \& Jacoby, R. (2004). Unmet treatment needs of older prisoners: a primary care survey. Age and Ageing, 33(4), 396-398. Retrieved from <Go to $|S|>: / / 000222403400015$

Fazel, S., Hope, T., O’Donnell, I., Piper, M., \& Jacoby, R. (2001). Health of elderly male prisoners: worse than the general population, worse than younger prisoners. Age and Ageing, 30(5), 403-407. Retrieved from <Go to ISI>://000172236800012

Freshwater, D., Cahill, J., Walsh, E., Muncey, T., \& Esterhuizen, P. (2012). Art and Science in Health Care Research: Pushing at Open Doors or Locked in Institutions? Qualitative Health Research.

Giblin, Y., Kelly, A., Kelly, E., Kennedy, H. G., \& Mohan, D. (2012). Reducing the use of seclusion for mental disorder in a prison: implementing a high support unit in a prison using participant action research. International Journal of Mental Health Systems, 6(1), 2. doi:10.1186/1752-4458-6-2 
Ginn, S. (2012). Elderly prisoners. BMJ, 345(oct15 4), e6263-e6263. doi:10.1136/bmj.e6263

Grant, A. (1999). Elderly Inmates: Issues for Australia. Australian Institute of Criminology trends \& issues in crime and criminal justice, 115, 1-6.

Grubin, D., Carson, D., \& Parsons, S. (2002). Report on New Reception Health Screening Arrangements: The Result of a Pilot Study in 10 Prisons. (D. of Health, Ed.). Newcastle: University of Newcastle.

Heidari, F., \& Galvin, K. (2003). Action learning groups: can they help students develop their knowledge and skills? Nurse Education in Practice, 3(1), 49-55. doi:10.1016/S14715953(02)00054-9

Her Majesty's Chief Inspector of Prisons. (2008). Older prisoners in England and Wales: a follow-up to the 2004 thematic review by HM Chief Inspector of Prisons. Retrieved March 2, 2013, from http://www.justice.gov.uk/downloads/publications/inspectoratereports/hmipris/thematic-reports-and-researchpublications/older_prisoners_thematic-rps.pdf

Holloway, I., \& Todres, L. (2010). Grounded Theory. In K. Gerrish \& A. Lacey (Eds.), The Research Process in Nursing (6th ed.). Oxford: Wiley Blackwell.

Hoogwerf, L., Frost, D., \& McCane, T. (2010). The Ever-Changing Discourse of Practice Development: Can We All Keep Afloat? In A. Gerrish \& A. Lacey (Eds.), The Research Process in Nursing (6th ed.). Oxford: Willly Blackwell.

Lamont, S., Brunero, S., \& Russell, R. (2010). An exploratory evaluation of an action learning set within a mental health service. Nurse education in practice, 10(5), 298-302. doi:10.1016/j.nepr.2010.01.002

Loeb, S. J., \& AbuDagga, A. (2006). Health-related research on older inmates: An integrative review. Research in Nursing \& Health, 29(6), 556-565. doi:10.1002/nur.20177

McGill, I., \& Brockbank, A. (2004). The Action Learning Handbook. London: Routledge Falmer.

Menzies-Lyth, I. (1988). Containing Anxiety in Institutions, Selected Essays, Volume 1. London: Free Association Books.

Meyer, J. (2010). The Research Process in Nursing. In A. Gerrish \& A. Lacey (Eds.), Action Research. Oxford: Wiley Blackwell.

Meyer, J. M. (2010). Antipsychotics and metabolics in the post-CATIE era. Current Topics in Behavioral Neurosciences, 4, 23-42. Retrieved from http://www.ncbi.nlm.nih.gov/pubmed/21312396

Ministry of Justice. (2004). White paper on crime 2004: Treatment of Offenders. 
Ministry of Justice. (2013). Offender Management Caseload Statistics 2013.

Munn-Giddings C, McVicar, A., \& Smith, L. (2008). Systematic review of the update and design of action research in published nursing research, 2000-2005. Journal of Research in Nursing, 13(6), 465-477.

Senior, J., Forsyth, K. J., Walsh, E., O'Hara, K., Stevenson, C., Hayes, A. J., Short, V., et al. (2013). Health and Social Care Services for Older Male Adults in Prison: the identification of current service provision and piloting of an assessment and care planning model. Health Serv Deliv Res, 1(X).

Snoeren, M. M., Niessen, T. J., \& Abma, T. A. (2011). Engagement enacted: Essentials of initiating an action research project. Action Research, 10(2), 189-204. doi:10.1177/1476750311426620

Snyder, C., Van Wormer, K., Chadha, J., \& Jaggers, J. W. (2009). Older adult inmates: The challenge for social work. Social Work, 54(2), 117-124. Retrieved from http://ovidsp.ovid.com/ovidweb.cgi?T=JS\&CSC=Y\&NEWS=N\&PAGE=fulltext\&D=psyc6\& $\mathrm{AN}=2009-04480-003$

Uzoaba, J. H. E. (1998). Managing older offenders: Where do we stand? (Report No. R-70). Ottawa, Ontario, Canada.

Walsh, E. (2009). Partnership work with health professionals in segregation units. Prison Service Journal, 181(34-36).

Walsh, E., \& Bee, A. (2012). Developing a learning environment in three prisons. International Practice Development Journal, 2(1), 1-15.

Walsh, E., \& Freshwater, D. (2006). Managing practice innovations in prison health care services | Practice | Nursing Times. Nursing Times, 102(7), 32-34. Retrieved from http://www.nursingtimes.net/nursing-practice/clinical-zones/management/managingpractice-innovations-in-prison-health-care-services/203375.article

Walsh, E., \& Freshwater, D. (2009). The mental health awareness of prison staff in England and Wales. Journal of Correctional Healthcare, 15(4), 302-309.

Williams, J. (2012). Social care and older prisoners. Journal of Social Work. doi:10.1177/1468017311434886 